удК 323(73)

\title{
Т.Б. Румяниева
}

\section{ПОЛИТИКА ПРАВИТЕЛЬСТВ США ПО РАЗВИТИЮ ПРОИЗВОДСТВЕННЫХ И ТЕХНОЛОГИЧЕСКИХ ВОЗМОЖНОСТЕЙ МАЛЫХ И СРЕДНИХ ПРЕДПРИЯТИЙ (1980-1990-е гг.)}

\begin{abstract}
Исследуются усилия правительств Соединенных Штатов Америки Р. Рейгана, Дж. Буша-старшего и Б. Клинтона по преодолению технологического отставания США от своих ближайших экономических конкурентов, в первую очередь - Японии. Для преодоления этого технологического разрыва американские правительства инициировали две масштабные программы, нацеленные на развитие производственных и технологических возможностей малых и средних предприятий Соединенных Штатов: Программа партнерств по расширению производства и Программа развития передовых технологий. Ключевые слова: США; инновационная политика; малые и средние предприятия.
\end{abstract}

В начале 1980-х гг. сфера производства США начала проигрывать Японии. В бытовой электронике, производстве стальных изделий и в других отраслях промышленности американские товары по сравнению с японскими выглядели менее качественными, производственные процессы - устаревшими, процесс разработки производственных инноваций - находящимся в состоянии застоя [1]. Профессор Ф. Шапира из Технологического института Джорджии, работавший в качестве эксперта в Управлении оценки технологий Конгресса США, отмечал, что к середине 1980-х гг. конкуренция со стороны Японии стала настолько устрашающей, что он и другие его коллеги начали учить японский язык, чтобы лучше понимать конкурентные преимущества «Страны восходящего солнца» [2]. Например, по такому важному показателю технологического развития страны, как количество заявок на патенты на изобретения, Япония в 1986 г. находилась на первом месте в мире (2 388 заявок на 1 млн жителей), в то время как США - только на 10-м (271 заявка на 1 млн жителей) [3].

Для того чтобы преодолеть технологическое отставание от Японии, республиканские правительства Р. Рейгана и Дж. Буша-старшего стали уделять особое внимание стимулированию развития контрактных отношений с мелким бизнесом, в особенности в сфере научно-исследовательских и опытно-конструкторских работ (НИОКР). Стали возникать партнерства по принципу «правительство - промышленность», основанные на привлечении частного капитала, благодаря которому, как были убеждены республиканцы, можно добиться экономического роста. Но помимо частных предпринимательских инициатив, были необходимы федеральные инвестиции в технологии.

Ряд крупных законодательных инициатив, принятых Конгрессом в 1980-е гг., демонстрировали новый акцент политики США на развитии партнерств федерального правительства и американской промышленности. К их числу относятся Закон о технологических инновациях Стивенсона Уайдлера, 1980 (StevensonWydler Technology Innovation Act), Закон Бея-Доула о патентах университетов и малого бизнеса, 1980 (the Bayh-Dole University and Small Business Patent Act), Закон о развитии инноваций в малом бизнесе, 1982 (the Small Business Innovation Development Act), Закон о национальных совместных исследованиях, 1984 (the National Cooperative Research Act), Закон о передаче
Федеральных технологий, 1988 (the Federal Technology Transfer Act), Комплексный Закон о торговле и конкурентоспособности, 1988 (the Omnibus Trade and Competitiveness Act), Закон о передаче технологий, связанных с национальной конкурентоспособностью, 1989 (the National Competitiveness Technology Transfer Act) [4. P. 38].

В соответствии с Законом о торговле и конкурентоспособности был создан Национальный институт стандартов и технологий (НИСТ) в целях содействия экономическому росту США за счет партнерства с промышленностью по вопросам разработки и применения новых технологий и стандартов. Миссия лабораторий НИСТ заключалась в удовлетворении нужд промышленности США в плане технологической инфраструктуры, включая стандарты, измерительные технологии, оценку данных, моделирование производственных процессов, испытания продукции, а также технологии оценки качества [5].

Закон о торговле и конкурентоспособности 1988 г. положил начало двум экспериментальным программам, осуществлявшимся под патронажем Национального института стандартов и технологии: Программе партнерств по расширению производства (The Manufacturing Extension Partnership, далеe - Программа партнерств) и Программе развития передовых технологий (The Advanced Technology Program, далее Программа технологий).

Целью Программы партнерств по расширению производства являлось предоставление технической помощи и поддержки в области менеджмента для малого и среднего бизнеса. Эта программа задумывалась как составная часть действий правительства США в ответ на потерю позиций перед Японией в области производства высокотехнологичной продукции [2].

Программа начала реализовываться в 1989 г. и изначально задумывалась как программа по созданию центров производственных технологий (Manufacturing Technology Centers) для предоставления услуг малым и средним предприятиям. Выделенные на реализацию программы средства по итогам проведения конкурсного отбора из 36 заявок были направлены на создание трех пилотных региональных центров: 1) Центр производственных технологий в г. Кливленд, штат Огайо; 2) Северо-восточный центр производственных технологий в политехническом университете в г. Троя, штат Нью-Йорк и 3) Юго-восточный центр 
производственных технологий в университете Южной Каролины в г. Коламбия, штат Южная Каролина.

В период 1990-1992 гг. программа расширилась и охватила еще четыре штата. Были созданы: Среднезападный центр производственных технологий в институте промышленных технологий в г. Анн-Арбор, штат Мичиган; Среднеамериканский центр производственных технологий в корпорации технологических предприятий в г. Оверленд-Парк, штат Канзас; Центр производственных технологий г. Миннеаполис (штат Миннесота) и Калифорнийский центр производственных технологий в колледже г. Торранс [6].

Основная задача созданных региональных центров заключалась в совершенствовании производственных и технологических возможностей малых компаний США. Конгресс Соединенных Штатов подчеркивал важность участия в данной программе промышленности, университетов, правительств штатов, федеральных агентств и национальных лабораторий, входивших в структуру НИСТ [7]. Начав свою работу, руководители первых семи созданных центров быстро осознали, что трансфер передовых технологий, на который делал ставку НИСТ, не соответствовал потребностям малых и средних компаний США, которые, как оказалось, прежде всего, нуждались в услугах по внедрению систем качества, планировке производственных помещений, автоматизации оборудования.

В связи с этим Р. Килмер, представитель руководства НИСТ, отмечал, что существует разрыв между потребностями предприятий, ориентированных на инновационное производство, и тем, что изобретается или разрабатывается на самом деле. Например, некоторые виды технологий, которые разрабатывались в Национальном институте стандартов и технологий, такие как передовые образцы робототехники, были не нужны малым и средним предприятиям, т.е., в американском понимании, таким предприятиям, в которых были заняты не более 500 работников. «Мы должны менять нашу политику и вместо предложения технологий, которые под силу разработать лабораториям НИСТ, ориентироваться на то, что малым и средним предприятиям действительно необходимо», - заявлял Р. Килмер. - «Это, кроме всего прочего, означает научиться шире смотреть на все производство, видеть не только отдельную техническую деталь, но и все остальное: финансирование, развитие трудовых ресурсов, маркетинг и продажи» [2].

Ключевым аспектом деятельности региональных производственных центров было взимание платы с компаний за предоставляемые услуги. Причем это делалось не столько для того, чтобы покрывать расходы на реализацию программы, сколько для мотивации производителей к осознанному участию в модернизации производства. Таким образом, Программа партнерств становилась государственно-частным объединением, которое реализовалось по схеме долевого финансового участия в программе: $1 / 3$ составляли средства федерального бюджета, 1/3 - средства местного, регионального правительства либо частных юридических лиц, 1/3 - оплата компании - получателя услуг.

Подобная финансовая схема явилась одним из факторов успешной реализации программы на терри- тории США. Причин тому было несколько. Вопервых, региональные производственные центры имели мощный стимул к поиску новых организацийпартнеров и предоставлению именно тех услуг, в которых нуждались малые и средние предприятия. Вовторых, сами предприятия-клиенты имели сильную мотивацию, так как вкладывали в модернизацию производства собственные средства. В-третьих, частичная оплата услуг со стороны федерального, регионального или местного бюджета делала услуги региональных производственных центров более доступными для малых и средних предприятий [1].

В результате к концу 1990-х гг. региональные производственные центры работали с приблизительно 30 тыс. малыми и средними предприятиями в рамках более 9 тыс. различных проектов. И тот же Р. Килмер мог с гордостью заявить, что в результате реализации Программы партнерств спрос малых и средних предприятий и предложение технологий со стороны НИСТ во многом совпадали. Он отмечал также, что в первые годы реализации Программы ее задача состояла в том, чтобы создать региональные производственные центры и начать работу. К концу 1990-х гг. наступило время для интеграции отдельных центров в единую сеть, с тем, чтобы не только повысить производительность малых и средних предприятий, но и научить их мыслить стратегически, т.е. думать о технологиях будущего [2].

С точки зрения Р. Килмера, новые задачи для малых и средних предприятий состояли в том, чтобы попытаться ответить на такие вопросы: «Как добиться роста компании? Как достичь увеличения объема продаж существующих продуктов? Как попасть на новые рынки за счет экспорта?» Р. Килмер выделял пять, по его мнению, ключевых областей, к которым должно быть приковано внимание руководителей подобных предприятий:

- непрерывное совершенствование;

- технология ускорения;

- новые цепочки поставок;

- устойчивость развития;

- трудовые ресурсы [Там же].

К концу XX в. спрос на услуги центров стал меняться в сторону бережливого производства, сертификации качества, чему во многом способствовало резкое развитие малозатратного производства в мире, особенно в Китае. Программа партнерств и услуги, предоставляемые в ее рамках региональными производственными центрами, оказались востребованы и сфокусированы на услугах, ориентированных на расширение малых компаний, на развитие их инновационного потенциала. Кроме того, просматривалось расширение охвата участников программы от индивидуальных компаний до производственно-сбытовых цепочек предприятий и производственных сообществ [1].

Самым активным сторонником мероприятий, направленных на развитие технологической и промышленной конкурентоспособности США, был сенатор из Южной Каролины Э.Ф. Холлингс, который в 1988 г. внес законопроект о технологической конкурентоспособности (Technology Competitiveness Act of 1988), ставший частью Закона о торговле и конкурен- 
тоспособности 1988 г. [7]. По праву сенатора Холлингса можно было бы назвать главным инициатором Программы партнерств, он способствовал ее принятию и оказывал поддержку ее реализации в течение всего периода своей службы в Сенате до 2005 г.

Э.Ф. Холлингс так объяснял свою позицию: «На протяжении длительного времени я видел какие трудности испытывают наши малые предприятия, осваивая новые производственные технологии. Японцы и немцы ушли далеко вперед в помощи своему бизнесу. И я видел собственными глазами, еще когда был губернатором (штата Южная Каролина в 1959-1963 гг. - T.P.), какой существует разрыв между исследованиями в агрономии и тем, как они доводились до сведения наших фермеров. Потому-то я и предложил создать сеть центров производственных технологий для того, чтобы делиться советами и помогать малым предприятиям воспользоваться теми преимуществами технологических открытий, которые им мог предоставить НИСТ» [8. Р. 235]. Вклад Э.Ф. Холлингса в создание Программы партнерств был столь весом, что после выхода сенатора на пенсию эта программа была переименована в его честь и стала носить название Программа развития партнерств по расширению производства имени Холлингса (Hollings Manufacturing Extension Partnership) [1].

В 1992 г. вопрос технологического отставания Соединенных Штатов от Японии стал предметом предвыборной программы кандидата в президенты от демократов Б. Клинтона. Он заявлял, что уже не только Япония, но и Германия превосходили Америку в экономическом отношении во многом благодаря тому, что политика правительств этих стран была ориентирована на поддержку потенциальных областей развития, в то время как администрация Дж. Бушастаршего предпочитала субсидировать «классические» отрасли, такие как нефтяная промышленность и сельское хозяйство. Эти отрасли были важны с политической точки зрения, но они мало что могли дать в плане создания новых рабочих мест и появления новых предпринимателей, в отличие от высокотехнологичных отраслей [9. С. 477]. Предвыборный штаб Б. Клинтона активно использовал в качестве примера ошибочной политики действовавшей администрации заявление ее представителя К. Хиллз о том, что с точки зрения американской экономики совершенно «неважно, что экспортируют США: картофельные чипсы или кремниевые чипы» [Там же. С. 476].

Однако несмотря на предвыборную риторику, Б. Клинтон, одержав победу на выборах президента США, во многом продолжил политику своих предшественников по развитию Программы партнерств. Первоначально концепция создания региональных центров технологических инициатив предполагала создание около 10-25 таких центров по всей стране. В период 1993-1995 гг. при помощи программы реинвестирования технологий Департамента обороны число этих центров увеличилось до 44 .

В 1994 г. произошла реструктуризация программы по созданию центров производственных технологий. Прямое финансирование обновленной программы позволило создать еще 36 региональных центров в период 1995-1996 гг., таким образом общее их число достигло 70. Позже отдельные центры в штатах НьюЙорк и Огайо объединились, и к началу XXI в. в 50 штатах США и Пуэрто-Рико действовала национальная сеть из 60 центров производственных технологий. Для развития промышленности создание этой сети было огромным шагом вперед, однако само по себе наличие сети не являлось достаточным, предстояло еще понять, в каких услугах нуждались американские предприятия.

Анализируя результаты реализации Программы партнерств, Ф. Шапира заявлял: «Мы живем в эпоху глобальной конкуренции. Наши компании конкурируют с компаниями по всему миру. Эта программа является одним из основных способов, которым мы пытаемся стимулировать наши малые и средние предприятия быть продуктивными, работать на экспорт, а также для подготовки высококвалифицированных работников. В эту эпоху глобальной конкуренции, мы должны быть уверены в том, что программа сконфигурирована таким образом, что она позволит решить не только существующие проблемы, но и дать адекватный ответ на будущие вызовы» [1].

Как уже отмечалось, другой инициативой, направленной на преодоление технологического отставания США, стала Программа развития передовых технологий. Она была задумана для повышения конкурентоспособности США, а также для того, чтобы создать условия, при которых экономика США выигрывает от федеральных инвестиций в НИОКР, реализуемых на базе партнерств. Программа технологий находилась в ведении Национального института стандартов и технологий Департамента торговли США и была нацелена на разделение затрат с промышленностью для ускорения развития и широкого распространения новых технологий с высокой степенью риска, которые обещают большие экономические выгоды для страны. Программа была направлена на преодоление разрыва между продукцией научно-исследовательских лабораторий и рынком и оказывала поддержку компаниям, осуществляющим разработку:

- новых и перспективных технологий, которые могли способствовать появлению и развитию новых и существенно улучшенных продуктов, производственных процессов и услуг с возможностью применения в различных областях;

- технологий, развитие которых часто включали в себя сложные «системные» проблемы, требующие совместных усилий нескольких организаций;

- технологий, которые в силу высокой степени риска вряд ли могли быть разработаны отдельными фирмами или развивались бы слишком медленно для того, чтобы конкурировать в быстро меняющемся мире рынка без поддержки со стороны Программы развития передовых технологий.

При этом компании сами разрабатывали проекты, готовили заявку в программу, обеспечивали софинансирование и выполняли проекты (часто в сотрудничестве с университетами и федеральными лабораториями). Роль Программы заключалась в определении наиболее перспективных проектов, требующих поддержки извне, и вложении финансовых средств на 
принципах совместных расходов. Программа финансировала технические исследования, а не разработку продуктов. Гранты оформлялись в форме контрактов о совместных договоренностях. Это имело ключевое значение, так как предусматривало разделение ответственности за развитие проекта между Национальным институтом стандартов и технологий и фирмами. При этом важно отметить, что малые компании конкурировали наравне с крупными предприятиями за получение грантов.

Программа имела ряд особенностей, которые в совокупности отличали ее от других государственных программ, направленных на поддержку технологий. В их числе - сочетание инициативы промышленности в выявлении перспективных областей технологии и лидерство в отрасли в планировании и реализации совместных проектов. Процесс отбора проектов включал техническую и экономическую оценку и учитывал наличие партнерских связей с другими компаниями, а также университетами и лабораториями. Для того чтобы войти в число победителей Программы по итогам отбора, заявки должны были содержать четко сформулированные технические и экономические цели и демонстрировать не только перспективы работы, но и конкретные потребности в финансировании со стороны Программы. В рамках Программы развития передовых технологий поддержка предоставлялась отобранным компаниям на определенный период времени. Компания - победитель программы могла получить до 2 млн долл. на проведение НИОКР сроком на 3 года. Условием для крупных компаний было вложение собственных средств в объеме не менее $60 \%$ от общего объема финансирования проекта. Совместные предприятия могли получить поддержку сроком на 5 лет.

В период с 1990 по 2000 г. в рамках реализации Программы развития передовых технологий был проведен 41 конкурсный отбор, по итогам которых выделено 522 грантов на общую сумму в размере около 1,640 млрд долл. Получателями грантов стали 1162 организаций и приблизительно такое же число субподрядчиков. Университеты и независимые некоммерческие исследовательские организации играли важную роль участников проектов, реализованных в рамках Программы. Университеты приняли участие в реализации более чем половины проектов, при этом общее число университетов участников достигло 176 [4. P. 40]. На конкурсной основе в рамках Программы поддержку получили компании, разрабатывавшие новые технологии в разных сферах. К их числу относятся адаптивные обучающие системы, компоненты программного обеспечения, хранение цифровых данных, информационная инфраструктура для здравоохранения, производственная инфраструктура для сферы микроэлектроники, производственные технологии для фотоники, автотранспортные средства и печатные платы, инженерные технологии по созданию новых биологических тканей и инструменты для ДНК-диагностики. Эти технологии являлись перспективными, но рисковыми.

Автором инициативы Программы развития передовых технологий был все тот же сенатор Э. Хол- лингс, а первоначальные ассигнования на программу были небольшими, всего 10 млн долл. в 1990 г. [4. Р. 39]. Администрация Дж. Буша-старшего курировала первую реализацию программы в Национальном институте стандартов и технологий, после чего рекомендовала существенно увеличить объем финансирования программы в государственном бюджете на 1993 г. [Ibid. P. 31].

Начиная со скромного финансирования в первый год реализации, программа выросла при поддержке конгресса до более чем 60 млн долл. в последние годы правления администрации Буша. Администрация Клинтона сделала акцент на развитие программ в сфере гражданских технологий, стремясь выровнять расходы на военные и гражданские НИОКР и поощряя дальнейшее развитие партнерских отношений между правительством и промышленностью для восстановления конкурентоспособности США. В рамках этих усилий администрация Клинтона не только объявила Программу развития передовых технологий в числе ключевых приоритетов новой технологической инициативы США [10], но и значительно увеличила объем Программы, разработала Программу реинвестирования технологий (the Technology Reinvestment Program) с целью облегчения адаптации к концу холодной войны, а также Программу развития транспортных средств следующего поколения (the Program for the Next Generation Vehicle).

Существенное увеличение финансирования Программы развития передовых технологий и быстрое внедрение других программ, ориентированных на разработку технологий, вызвали также и значительную оппозицию к Программе, которая, возможно, способствовала возрождению национальной дискуссии о надлежащей роли правительства в стимулировании новых технологий. По существу, после начального скачка в объеме финансирования Программы развития передовых технологий до 340 млн долл. в первые годы администрации Клинтона, Программа стабилизировалась на уровне около 200 млн долл. ежегодно до конца 1990-х гг., после чего последовало сокращение объема финансирования Программы в 2000 финансовом году, частично связанное с неспособностью освоить в полном объеме выделенные средства. Отчасти в результате административной ошибки в расчетах, бюджет Программы на 2000 финансовый год резко сократился до 143 млн долл. (с 197 млн долл. в предыдущем году). В бюджете 2001 финансового года произошло возвращение к объему в 191 млн долл., включая переходящие остатки прошлых лет [4. Р. 42].

Таким образом, разработанная в 1988 г. при администрации Рейгана, получившая первое финансирование в 1990 г. при администрации Буша и достигшая масштабного развития при администрации Клинтона Программа развития передовых технологий представляла собой один из элементов усилий правительства США по восстановлению и повышению конкурентоспособности экономики США. Посредством Программы государство предоставляло гранты и обеспечивало софинансирование расходов, связанных с проведением НИОКР и разработкой конкурентоспособных передовых технологий, обладающих высокой степенью 
риска, широким коммерческим потенциалом и способностью приносить пользу обществу в целом.

Что касается технологического отставания от Японии, то к концу президентского правления Б. Клинтона Япония по-прежнему занимала первое место в мире по количеству поданных заявок на патенты на изобретения, хотя США и поднялись по этому показателю с 10-го на 4-е место к 2000 г. [11]. Однако Соединенные Штаты продемонстрировали самый значительный в мире количественный рост по балансу платежей за технологии в период с 1985 по
1997 г.: с 5 до 24 млрд долл., в то время как аналогичные японские показатели за этот же период были скромнее: от минуса 0,2 млрд (т.е. Япония на самом деле в середине 1980-х гг. больше импортировала технологии, чем экспортировала) до 3 млрд долл. [12]. Важно отметить то, что Япония сыграла роль раздражителя для американского руководства, стимулировав разработку и внедрение важных инициатив, в числе которых были Программа партнерств по расширению производства и Программа развития передовых технологий.

\section{ЛИТЕРАТУРА}

1. NIST Hollings Manufacturing Extension Partnership. URL: http://www.nist.gov/mep/about/history.cfm (дата обращения: 18.01.2017).

2. Strengthening American Manufacturing: The Role of the Manufacturing Extension Partnership: Summary of a Symposium, 2013. URL: https://www.nap.edu/read/18329/chapter/3\#18 (дата обращения: 18.01.2017).

3. International Statistics. URL: http://www.nationmaster.com/country-info/compare/Japan/United-States/Industry\#1986 (дата обращения: 19.01.2017).

4. The Advanced Technology Program: Assessing Outcomes / ed. by C.W. Wessner. Wash. : National Research Council, 2001. URL: http://www.nap.edu/catalog/10145.html (дата обращения: 15.01.2017).

5. An Assessment of the National Institute of Standards and Technology Programs. Fiscal Year 1994. Wash., 1994. URL: http://www.nap.edu/read/9198/ (дата обращения: 19.01.2017).

6. Dave Cranmer. Reflections on 25 years of the MEP Program. URL: http://nistmep.blogs.govdelivery.com/25-year-reflections/ (дата обращения: 11.01.2017)

7. South Carolina Manufacturing Extension Program. URL: http://www.scmep.org/history/ (дата обращения: 17.01.2017).

8. Hollings E.F. Making Government Work. Columbia : University of South Carolina Press, 2008.

9. Клинтон Б. Моя жизнь : пер. с англ. М., 2005.

10. Technology for America's Economic Growth, A New Direction to Build Economic Strength. Washington: The White House office of the press secretary, 1993. URL: http://ntl.bts.gov/lib/jpodocs/briefing/7423.pdf (дата обращения: 15.01.2017).

11. International Statistics. URL: http://www.nationmaster.com/country-info/compare/Japan/United-States/Industry\#2000 (дата обращения: 19.01.2017).

12. Organization for Economic Co-operation and Development. URL: https://www.oecd.org/sti/sci-tech/2087228.pdf (дата обращения: 19.01.2017).

Статья представлена научной редакцией «История» 23 февраля 2017 г.

THE US GOVERNMENT POLICY AIMED AT THE DEVELOPMENT OF THE INDUSTRIAL AND TECHNOLOGICAL CAPACITY OF SMALL AND MEDIUM-SIZED ENTERPRISES (1980S-1990S)

Vestnik Tomskogo gosudarstvennogo universiteta - Tomsk State University Journal, 2017, 418, 137-142. DOI: $10.17223 / 15617793 / 418 / 17$

Tatiana B. Rumyantseva, Tomsk State University (Tomsk, Russian Federation). E-mail: rtb98@mail.ru Keywords: United States; innovation policy; small and medium-sized enterprises.

The United States is one of the most technologically advanced countries in the world. At the same time, during the period of not less than 50 years it has been experiencing strong competition from innovative economies of such countries as Japan and Germany. In order to reduce the USA's technological lag with Japan, the Republican government of Ronald Reagan and George H.W. Bush started to pay special attention to the development of partnerships between government and small or medium-sized business, especially in the field of research and development (R\&D). The Republicans were convinced that economic growth could be achieved by attraction of private capital for creation of partnerships based on the "government-industry" principle. Moreover, federal investments in technology were also necessary. In 1988, the National Institute of Standards and Technology (NIST) was created. Its aim was to promote the economic growth of the United States through partnerships with industry in the sphere of development and application of new technologies and standards. The mission of NIST laboratories was to satisfy needs of the US industry in technological infrastructure, including standards, measuring technology, data evaluation, simulation of manufacturing processes, product testing and quality control technology. The Omnibus Trade and Competitiveness Act of 1988 marked the beginning of two experimental programs carried out under the auspices of the National Institute of Standards and Technology: the Manufacturing Extension Partnership (MEP) and the Advanced Technology Program (ATP). The aim of the first program was to provide technical assistance and support in the field of management to small and medium-sized companies. MEP was launched in 1989 and was originally considered as a program for creation of manufacturing technology centers to provide services to small and medium-sized enterprises. The main task of the established regional centers was to improve the manufacturing and technological capacity of US small companies. Qualified MEP centers worked directly with small and medium manufacturing firms providing expertise, services and assistance directed to foster growth, improve supply chain positioning, leverage emerging technologies, upgrade manufacturing processes, develop work force training and apply and implement new information. Implementation of the MEP program had led to several important results. First, the regional manufacturing centers received a powerful incentive to find new partner organizations and provide services needed by small and medium-sized enterprises. Second, the enterprises-customers also had strong motivation because they invested their own funds in the manufacturing process modernization. Third, partial payment for services by the federal, regional or local government made services of regional centers more affordable to small and medium-sized enterprises. As a result, by the end of the 1990s, regional manufacturing centers had worked on more than 9000 various projects with about 30000 small and medium-sized enterprises. Another initiative aimed at reducing the USA's technological lag, was development of the Advanced Technology Program. It was designed to bridge the gap between the research lab and the marketplace, to enhance US competitiveness, as well as to create conditions under which the US economy could benefit from partnership-based federal 
investments in R\&D. This program was aimed to share federal costs with industry in order to accelerate development and wide dissemination of new high-risk technologies that promised greater economic benefits for the country. The ATP funding was directed to technical research but not product development. Companies, either singly or jointly, conceived, proposed and executed all projects, often in collaboration with universities and federal laboratories. The ATP shared the cost for projects that were selected for a limited time. Single-company awardees could receive up to $\$ 2$ million for R\&D activities for up to three years. Larger companies had to contribute at least sixty percent of the total project cost. Joint ventures could receive funds for R\&D activities for up to five years. Thus, developed in 1988 under the Reagan administration, first funded in 1990 under the Bush administration, and reached the largescale development under the Clinton administration, the Advanced Technology Program represented one element of the U.S. government's efforts to restore and enhance the competitiveness of the U.S. economy. It provided cost-shared, competitive grants to industry to support R\&D on high-risk, cutting-edge technologies with broad commercial potential and societal benefit.

\section{REFERENCES}

1. Nist.gov. (n.d.) NIST Hollings Manufacturing Extension Partnership. [Online] Available from: http://www.nist.gov/mep/about/history.cfm. (Accessed: 18th January 2017).

2. Nap.edu. (2013) Strengthening American Manufacturing: The Role of the Manufacturing Extension Partnership: Summary of a Symposium. [Online] Available from: https://www.nap.edu/read/18329/chapter/3\#18. (Accessed: 18th January 2017).

3. Nationmaster.com. (1986) International Statistics. [Online] Available from: http://www.nationmaster.com/country-info/compare/Japan/UnitedStates/Industry\#1986. (Accessed: 19th January 2017).

4. Wessner, C.W. (ed.) (2001) The Advanced Technology Program: Assessing Outcomes. Washington: National Research Council, 2001. [Online] Available from: http://www.nap.edu/catalog/10145.html. (Accessed: 15th January 2017).

5. Nap.edu. (1994) An Assessment of the National Institute of Standards and Technology Programs. Fiscal Year 1994. Washington. [Online] Available from: http://www.nap.edu/read/9198/. (Accessed: 19th January 2017).

6. Cranmer, D. (n.d.) Reflections on 25 years of the MEP Program. [Online] Available from: http://nistmep.blogs.govdelivery.com/25-yearreflections/. (Accessed: 11 th January 2017).

7. Scmep.org. (n.d.) South Carolina Manufacturing Extension Program. [Online] Available from: http://www.scmep.org/history/. (Accessed: 17th January 2017).

8. Hollings, E.F. (2008) Making Government Work. Columbia: University of South Carolina Press.

9. Clinton, W. (2005) Moya zhizn' [My life]. Translated from English by M. Nikol'skiy et al. Moscow: Al'pina Biznes Buks.

10. Ntl.bts.gov. (1993) Technology for America's Economic Growth, A New Direction to Build Economic Strength. Washington: The White House office of the press secretary. [Online] Available from: http://ntl.bts.gov/lib/jpodocs/briefing/7423.pdf. (Accessed: 15th January 2017).

11. Nationmaster.com. (2000) International Statistics. [Online] Available from: http://www.nationmaster.com/country-info/compare/Japan/UnitedStates/Industry\#2000. (Accessed: 19th January 2017).

12. Oecd.org. (n.d.) Organization for Economic Co-operation and Development. [Online] Available from: https://www.oecd.org/sti/scitech/2087228.pdf. (Accessed: 19th January 2017).

Received: 23 February 2017 